\title{
CONSTRUINDO GÊNERO NA INFÂNCIA: REFLEXÕES PARA UMA PARENTALIDADE NÃO-SEXISTA
}

\author{
Tathiany Rezende de Moura iD1
}

\section{Resumo}

Pensar sobre gênero, sexualidade e educação infantil demanda diferenciação entre o caráter biológico do caráter cultural e social dos papeis de gênero. Sexo está relacionado ao biológico, que não define os comportamentos masculino ou feminino, estes ligados a questões psicológicas e culturais, ou seja, ao gênero. Sexualidade é um elemento da configuração do ser humano, que começa a se desenvolver na infância num processo natural e cultural que influenciará o comportamento desde o nascimento até a morte. Neste trabalho, a autora busca encontrar ferramentas para refletir sobre uma parentalidade ativa para uma educação que promova a igualdade de gênero. Por volta dos 3 anos de idade, as crianças conseguem se definir como pertencentes a um determinado gênero, mas ainda sem identificar quais comportamentos são apropriados para membros desse grupo. As crianças reconhecem e definem o gênero utilizando exteriorizações reforçadas pelos adultos, que as educam a brincar de formas que influenciam e reforçam a ideologia. Ao brincar a criança desenvolve aspectos físicos, linguísticos, sociais e cognitivos e aprendem os atributos de personalidade mais apropriadas para o seu sexo. Assim como as formas de brincar, a linguagem utilizada pelos adultos pode marcar e produzir diferenças e reforçar a dualidade entre meninos e meninas. A desconstrução dessa dualidade propõe que as atividades físicas ou intelectuais, linguagens, brinquedos e brincadeiras, tratem as crianças sem a divisão de sexo ou gênero, considerando a faixa etária, mas sem expectativas de desempenho, habilidades inerentes ou atividades pré-determinadas socialmente relacionadas ao sexo ou ao gênero da criança.

Palavras-chave: Identidade de Gênero; Educação Infantil; Parentalidade.

\section{BUILDING GENDER IN CHILDHOOD: REFLECTIONS FOR NON-SEXIST PARENTALITY}

\section{Abstract}

Thinking about gender, sexuality and children education demands differentiation between biological character and cultural and social character of gender roles. Sex is related to biological, that doesn 't define male or female behaviors, those related to psychological and cultural issues, that is gender. Sexuality is an element of human configuration that begins to develop in childhood in a natural and cultural process that influences behavior from birth to death. In this paper, the author seeks to find tools to reflect on active parenting for an education that promotes gender equality.

${ }^{1}$ Doutoranda em Sociedade, Tecnologias e Políticas Públicas pelo Centro Universitário Tiradentes. Mestre em Saúde e Ambiente pela Universidade Tiradentes. Fisioterapeuta. Contato: tmoura@perineo.net

Perspectivas em Diálogo, Naviraí, v. 8, n. 16, p. 259-272, jan./abr. 2021. 
By the age of 3, children can define themselves as belonging to a particular gender, but still not identifying which behaviors are appropriate for members of that group. Children recognize and define gender using adult-reinforced externalizations that educate them to play in ways that influence and reinforce ideology. By playing, children develops physical, linguistic, social and cognitive aspects and learns the personality attributes most appropriate for his or her gender. Such as playing, adult language can mark and produce differences and reinforce duality between boys and girls. The deconstruction of this duality proposes that physical or intellectual activities, languages, toys and games, treat children without sex or gender division, considering the age group, but without expectations of performance, inherent skills or predetermined activities socially related to the child sex or gender.

Keywords: Gender Identity; Child Rearing; Parenting.

\section{Introdução}

Pensar sobre gênero, sexualidade e educação infantil seja na família ou na escola com o intuito de que a sociedade futura possa superar as desigualdades de gênero, preconceitos e crenças sociais acerca dos papéis desempenhados por homens e mulheres é uma tarefa que demanda o entendimento de conceitos que são discutidos atualmente mas que já há muito tempo vem sendo debatidos e estudados com a finalidade de entender o que difere o caráter biológico do caráter cultural e social de gênero.

Na perspectiva biológica, o que determina o sexo de uma pessoa é o tamanho das suas células reprodutivas (pequenas: espermatozoides, logo, macho; grandes: óvulos, logo, fêmea) (JESUS, 2012), ou seja, assim como definiu a socióloga Oakley (1972) o sexo designa o que é homem ou mulher, e está diretamente ligado a características físicas, como genitália externa e interna, gônadas, hormônios, cromossomos, etc. Porém, as características biológicas não definem o comportamento masculino ou feminino das pessoas: o que faz isso é a cultura, e isso muda de acordo com a cultura de que falamos (JESUS, 2012).

O gênero não considera unicamente as características biológicas e, por consequência, físicas. É um termo com conotações muito mais psicológicas e culturais do que biológicas; se os termos usados para designar sexo são macho e fêmea, os termos correspondentes para gênero são masculino e feminino podendo ser bem independentes do sexo biológico (STOLLER, 1968). A palavra gênero foi incluída no contexto social em decorrência dos movimentos sociais feministas, que ganharam força na década de 1960 em função da desigualdade de poder entre o masculino e feminino (SCOTT, 1999) e passaram a empregar o termo gênero ao invés de sexo, reforçando a ideia de que as diferenças entre homens e mulheres não dependiam do sexo biológico, mas dos fatores culturais nos quais as pessoas estavam inseridas (PEDRO, 2005).

A diferenciação entre sexo e gênero também foi questionada pela filósofa Judith Butler, que questionou a categoria gênero como sexo biológico considerando que gênero é a estilização repetida do corpo, um conjunto de atos que sofrem mudanças durante a vida do indivíduo e reconhecendo que gênero se confronta com diversas modalidades de identidades, não estando relacionado à orientação sexual e tampouco a outros aspectos da sexualidade (BUTLER, 1990). 
Segundo a Organização Mundial da Saúde (2006), sexualidade é parte integrante da personalidade de cada um, como uma energia motivada a encontrar amor, contato e intimidade, e se expressa na forma de sentir, nos movimentos das pessoas e como estas tocam e são tocadas, é ser sensual e sexual. A sexualidade influencia pensamentos, senti mentos, ações e integrações, portanto, a saúde física e mental. A sexualidade começa a se desenvolver na infância num processo natural e cultural desenvolvido desde as primeiras experiências afetivas do bebê com a mãe (RIBEIRO; DIAS, 2009).

Ao falar sobre sexualidade faz-se necessário diferenciá-la de sexo, pois tanto um bebê quanto um idoso que não tem vida sexual ativa tem a sexualidade como parte de sua formação humana. A sexualidade é um elemento da configuração do ser humano que influencia e influenciará todo o seu comportamento desde o momento do nascimento até a morte do indivíduo e se relaciona muito mais com aspectos psicológicos e comportamentais do homem do que com sua organização biológica (CÂMARA NETO, 2002).

Diante dos conceitos esclarecidos acima, o objetivo da autora deste trabalho é encontrar ferramentas para refletir sobre como é possível exercer uma parentalidade ativa no sentido de construir uma educação que promova a igualdade de gênero e que propicie que os papéis sociais desempenhados pelos futuros adultos sejam menos associados ao biológico e mais respeitosos às identidades de gênero.

\section{O gênero educação infantil}

A sociedade em que vivemos dissemina a crença de que os órgãos genitais definem se uma pessoa é homem ou mulher e que as crianças são ensinadas a agir e a ter uma determinada aparência, de acordo com o seu sexo biológico, mas que a construção da nossa identificação como homens ou como mulheres não é um fato biológico, é social (JESUS, 2012) a educação das crianças seja contexto no familiar ou escolar pode reproduzir o contexto social do gênero como sinônimo de sexo ou questionar esta realidade de modo que o gênero seja construído como cultural e social.

A maioria das crianças adota uma identidade de gênero entre 2 e 3 anos de idade, ou seja, as crianças já conseguem se definir como pertencentes a um determinado gênero (CAHILL, 1986), mas ainda estão muito longe de ter uma noção do posicionamento social que implica pertencer a determinado gênero. Embora as crianças se considerem irrevogavelmente membros de um determinado grupo de gênero, elas ainda não têm certeza sobre quais tipos de comportamentos são apropriados para membros desse grupo-e a compreensão de sua identificação de gênero ocorre ao longo da vida e não é baseada em seu conhecimento das coisas físicas e biológicas, mas no seu conhecimento da linguagem de identificação social e cultural que caracteriza a sociedade na qual nascem (CAHILL, 1986).

$O$ conceito de posicionamento de gênero permite compreender que os modos possíveis de as crianças construírem e assumirem o gênero não são decorrentes de uma inerência biológica concreta nem de uma inerência social abstrata, mas do confronto e do jogo em ações, que são múltiplas, complexas, contraditórias e dinâmicas. Muitas vezes as crianças se tornam resistentes e desafiam a imposição de estereótipos e, outras vezes, atualizam, reproduzem e acentuam esses mesmos estereótipos, inclusive porque esses posicionamentos são inseparáveis das diferentes 
posições relativas de poder e dominância que as crianças ocupam nas relações sociais entre pares, nas quais se cruzam categorias como gênero, idade, classe social, etnia, entre outras (FERREIRA, 2002).

Meninos e meninas desenvolvem seus comportamentos e potencialidades a fim de corresponder às expectativas de um modo singular e unívoco de masculinidade e de feminilidade em nossa sociedade e as expectativas em relação à diferença de comportamento que se deseja para o menino e para a menina, justificadas pelas diferenças biológicas, acabam proporcionando distintas vivências corporais e determinando os corpos infantis: meninos e meninas têm no corpo a manifestação de suas experiências (VIANNA; FINCO, 2009).

Essa perspectiva acaba criando dois polos considerados totalmente distintos, o feminino e o masculino, desconsiderando o ser como apenas criança e, desde tão pequenas, já caracterizadas pelo sexo biológico, quase nunca fisicamente aparente, mas que culturalmente e socialmente deixa claro as expectativas de comportamento e desempenho social para cada um dos dois grupos, não levando em conta afinidades, possibilidades, potencialidades e habilidades daquela criança.

\section{Coisas de meninas e coisas de meninos}

Para os adultos, o gênero é uma categoria útil para classificar, dividir, seriar e juntar as crianças (THORNE, 1993), utilizando exteriorizações dos atributos de gênero, e trazendo marcas dessa construção que ocorrem por meio da linguagem (nomes, títulos, formas de tratamento e pronomes), de artefatos materiais (vestimentas, cosméticos, bijuterias e acessórios) e de gestos e atividades e uma vez que os definidores do pertencimento sexual - os genitais - não estão visíveis no cotidiano, as crianças vão reconhecendo e definindo o gênero nelas mesmas e nos outros, por meio de objetos, acessórios, cortes de cabelo, gestos, voz etc. (HIRSCHAUER, 1993).

As fronteiras entre os gêneros não são fixas, são trabalhadas nas práticas culturais, sobretudo no brincar (THORNE, 1993). Na educação infantil o corpo ganha destaque: os gestos, os movimentos e as posturas são alinhavados socialmente; ganham determinado lugar e uma imagem, segundo padrões de conduta e valores culturais em que cada criança se insere, tornando indispensável pensar sobre práticas, habilidades e configurações corporais infantis e também sobre os modelos cognitivos nelas referenciados, como relações sociais de gênero, processadas, reconhecidas e valorizadas na e pela cultura na qual se inserem (VIANNA; FINCO, 2009).

Adultos educam crianças definindo em seus corpos diferenças de gênero, reforçando, às vezes inconscientemente, características físicas e comportamentos esperados para meninos e meninas, de forma que o que é valorizado para a menina não é, muitas vezes, apreciado para o menino, e vice-versa (FINCO, 2003). A feminilização e masculinização dos corpos está presente no controle dos sentimentos, no movimento corporal, no desenvolvimento das habilidades e dos modelos cognitivos de meninos e meninas está relacionado à força das expectativas que nossa sociedade e nossa cultura carregam, refletindo nos tipos de brinquedos que são permitidos e disponibilizados para as crianças, que aprendem o comportamento verdadeiros de meninos e meninas (VIANNA; FINCO, 2009). 
Na construção da dualidade entre meninos e meninas e as formas de brincar, há uma estreita ligação entre o que a publicidade de brinquedos infantis oferece e o desejo que se cria a partir disso. É notável a diferenciação feita por gênero, mesmo que brinquedos sejam de crianças. As imagens de "brinquedo de menina" em sites de pesquisa são, em sua grande maioria, de utensílios domésticos em miniatura, seguidas por bonecas e maquiagens, enquanto que "brinquedo de menino", aprece como bonecos de ação, super-heróis, carros dos mais variados tipos e cores, pistas automotivas ou armas em geral (GREGOVISKI; SILVA; HLAVAC, 2016).

Se durante o desenvolvimento cognitivo, as crianças são educadas a brincar de formas que influenciam e reforçam a ideologia que reproduz a submissão feminina e a sobreposição masculina, designando a decodificação dos papéis sociais e as atitudes inconscientes (SILVA, 2013). Esse padrão comportamental presente nas propagandas e por consequência nos brinquedos traz concepções sobre como as meninas são destinadas às atividades mais delicadas e com o cunho de cuidado e como os meninos são estimulados a atividades que promovam o movimento físico e o desenvolvimento de atividades de raciocínio (GREGOVISKI; SILVA; HLAVAC, 2016), vai culminar em estereótipos de gênero cada vez mais marcantes (CORDAZZO; VIEIRA, 2008):

[...] as crianças podem ser afetadas de dois modos: como consumidoras, já que os pequenos são um forte alvo de grandes empresas de brinquedos e jogos, e como futuros membros de uma comunidade machista, com papéis de gênero definidos previamente por uma cultura preconceituosa. Para aquelas que preferirem outros tipos de brinquedos, meninas que gostem de brinquedos designados para meninos e vice-versa, nossa sociedade pode ser muito cruel por não estar devidamente no padrão instituído, deixando famílias desamparadas e crianças extremamente confusas (GREGOVISKI; SILVA; HLAVAC, 2016, p. 97).

Vencer a dualidade entre as "coisas de menino" e as "coisas de menina" exige que a ideia de gênero determinada pelo componente biológico seja superada e o entendimento de que a criança não nasce com um comportamento social prédeterminado, mas que este comportamento sendo masculino ou feminino, é aprendido de acordo com o contexto social e cultural em que a criança está inserida.

Para promover uma educação igualitária e respeitosa às afinidades e habilidades da criança independente do sexo biológico e do comportamento social correspondente a ele e uma futura sociedade em que as desigualdades de gênero inexistam, pode-se começar a tratar 0 ato de brincar como ato das crianças, propiciando contato com diversos tipos de brincadeiras, brinquedos, cores, funcionalidades, narrativas e reproduções das funções sociais dos adultos sem que essas atividades sejam separadas e direcionadas a grupos de meninas e grupos de meninos mas a grupos de crianças.

\section{Brincadeiras de criança ou de meninos e meninas?}

O ato de brincar é importante pela relação com o prazer que dá ao indivíduo, mas também, no desenvolvimento de aspectos físicos, ligados ao sensorial e ao motor, correspondentes ao desenvolvimento de aptidões linguísticas, sociais e 
cognitivas e simbólicos, vivenciando algo que não podem ter no mundo real naquele momento e experimentando diferentes papeis sociais (CORDAZZO; VIEIRA, 2008).

Os brinquedos demonstram o que se espera daquele sujeito quando ele se tornar adulto (GREGOVISKI; SILVA; HLAVAC, 2016) e, por isso, meninos e meninas demonstram comportamentos, preferências competências, atributos de personalidade mais apropriadas para o seu sexo, seguindo, desde crianças, as normas e padrões estabelecidos. Por conseguinte, Vianna e Finco (2009, p. 275) analisam que "É também considerado comum que meninas e meninos desenvolvam seus comportamentos e potencialidades no sentido de corresponder às expectativas quanto às características mais desejáveis para o masculino e para o feminino", ou ainda que:

Meninos e meninas desenvolvem seus comportamentos e potencialidades no sentido de corresponder às expectativas quanto às características mais desejáveis para o que é definido como pertinente a um modelo singular e unívoco de masculinidade e de feminilidade em nossa sociedade (VIANNA; FINCO, 2009, p. 279).

Ao estudar as relações de gênero na infância, Belotti (1975) menciona que brinquedos compostos por elementos perfeitamente identificáveis e estruturados, tornam bem clara a diferenciação de brinquedos para meninas e brinquedos para meninos e que brinquedos neutros, próprios para meninas e meninos, são, em geral, compostos de materiais não-estruturados, como jogo de construção, mosaico, quebra-cabeça, jogos de encaixar, instrumentos musicais (BELOTTI, 1975).

Como seria possível, então, pensar o ato de brincar como atividade das crianças sem reforçar a ideia da dualidade entre feminino e masculino em que meninos e meninas precisam escolher entre brinquedos pré-determinados para seu sexo biológico e seu correspondente socialmente esperado de gênero? Como possibilitar que as crianças brinquem entre si sem que sejam impostas identidades de gênero?

A proposta desconstrutiva busca a desestruturação das dicotomias e problematiza a constituição de cada polo, demonstrando que cada um supõe e contém o outro, o que pode ser um dos primeiros passos no questionamento das relações de gênero (LOURO, 2000).

Ao observar as brincadeiras de meninos e meninas, de 4 a 6 anos, em um ambiente coletivo e público de educação, Finco (2005) analisou o modo como se relacionam e se manifestam culturalmente frente às questões de gênero e constatou, nas brincadeiras coletivas, meninos e meninas se revezando nos papéis masculinos ou femininos sem menosprezar ou desprezar e que a criança buscava um companheiro para brincar e vivenciar momentos agradáveis, não importando se é menino ou menina:

A variedade dos brinquedos e as diversas opções de brincadeiras favorecem para que todos os espaços sejam ocupados por meninas e meninos indiscriminadamente. As crianças brincam espontaneamente com os brinquedos que escolhem sem constrangimentos. Meninos participavam de brincadeiras como cuidar da casa, cozinhar, passar roupa, cuidar dos filhos, que são vistas como funções das mulheres, assim as crianças trocavam e experimentavam os papéis de gênero durante os momentos de brincadeira (FINCO, 2005, p. 9).

Sobre a escolha dos brinquedos, Finco (2205) enfatiza: 
Foi possível compreender a positividade das transgressões, nos momentos de brincadeiras, percebendo como meninos e meninas resistem aos padrões préestabelecidos, recriando e inventando novas formas de brincar, novas formas de ser. [...] As escolhas e utilização dos brinquedos pelas crianças foram pontos importantes de análise para refletir sobre as relações entre meninos e meninas. É importante ressaltar que os brinquedos são compreendidos como elementos culturais, portadores de significados e de um enredo social e as crianças estão a todos os momentos ressignificando e re-criando estes significados (FINCO, 2005, p. 11).

As conclusões da pesquisa de Daniela Finco (2005) estão alinhadas com a ideia de que mesmo "quando a disciplina insiste em fabricar corpos submissos e afeitos aos padrões tradicionais de gênero, esses corpos, mesmo ainda pequenos, insistem em resistir e rebelar-se" (VIANNA; FINCO, 2009). O conceito de criança transgressora, como sendo a criança que desafia as normas pressupostas provoca estranheza, mas mostra que é possível fazer educação produzindo diferenças:

O modelo binário masculino-feminino é apresentado diariamente para elas (as crianças em fase pré-escolar). A manutenção desse modelo binário depende do ocultamento das masculinidades e feminilidades alternativas, do silêncio sobre elas e de sua marginalização. É por meio desses "maus exemplos" que a sociedade reforça a associação unívoca e supostamente natural entre sexo e padrões de gênero (VIANNA; FINCO, 2009, p. 280).

A transgressão dos padrões socialmente aceitos costuma ser socialmente mal vista e ridicularizada, uma das maneiras mais eficientes de reafirmar que cada um teria que se conformar aos padrões tradicionais de gênero e, principalmente, ao lugar que lhe cabe na sociedade. São preconceitos que não resistem à razão, nem aos novos tempos e que continuamos a considerar verdades intocáveis, nos costumes e nas regras inflexíveis (VIANNA; FINCO, 2009, p. 281).

Em estudo observacional durante aulas de educação física para crianças de aproximadamente 5 anos, as autoras Mariano e Altmann (2015) relatam a atuação de um professor que, ao se dirigir com os alunos ao espaço previamente combinado, não propunha formação de filas e as crianças caminhavam acompanhando o professor de forma aleatória. O professor citado adotava uma metodologia de aula de forma a não incentivar a dualidade e promovia uma maior interação entre meninos e meninas:

Durante o período em que foram feitas as observações, o professor nunca dividiu as turmas por sexo. Sempre que as brincadeiras exigiam uma separação em grupos distintos, eles eram mistos. Uma organização menos formal possibilitava que as crianças se agrupassem de maneiras variadas, realizando suas próprias escolhas e vivenciando relações que não eram marcadas pela separação por sexo. Grupos de meninas e meninos, só de meninos ou de só de meninas formavam-se e dissolviam-se durante as aulas, sem que essa distinção despontasse como um elemento organizador da aula e dos conteúdos trabalhados (MARIANO; ALTMANN, 2015, p. 418).

Apesar da construção social dos papeis de gênero determinados para meninos e meninas e das expectativas relacionadas a tais papeis, as crianças podem questionar (mesmo que não verbalmente) as expectativas dos adultos com relação ao desempenho e envolvimento nas brincadeiras. Através da atitude física e interesse 
natural, as crianças podem se envolver em brincadeiras e utilizar brinquedos diferentes dos esperados para meninos ou meninas.

Atividades que não demandem um dualismo entre meninas e meninos, mas que, ao contrário disso, estimulem ou apenas deixem livre a formação de grupos mistos podem ser uma forma de promover autonomia e uma ferramenta para interação entre as crianças, promovendo a-igualdade de gênero.

Além de atividades que estimulem grupos mistos e promovam autonomia, a forma de comunicação com as crianças também pode ser usada com a intenção de promover uma igualdade de tratamento, em vez de utilizar a linguagem para agrupar de acordo com o sexo biológico, referir-se aos grupos como crianças e distribuir as atividades propostas em grupos mistos.

\section{Linguagem não-sexista}

A linguagem utilizada pelos adultos ao se comunicar com as crianças também pode ser uma ferramenta para uma educação não-sexista, que respeite, mas que não as separe e caracterize grupos de acordo com o sexo. A linguagem utilizada principalmente pelos professores, que tem convívio diário com grupos maiores de crianças do que o contexto familiar, suas expectativas e incentivos oferecidos em torno de um gênero, expressas por falas e gestos, e as atividades propostas durante as aulas podem marcar e produzir diferenças entre eles e elas (MARIANO, ALTMANN, 2016).

Durante aulas de educação física para educação infantil, pesquisadoras identificaram como a linguagem utilizada e o planejamento das aulas oferecia autonomia e liberdade às crianças frente às escolhas e à organização do grupo para as atividades:

Quando falava com as crianças, tanto para explicar as atividades, quanto para resolver qualquer outro tipo de situação durante a aula, como desentendimentos, o professor constantemente usava o termo "criança(s)". Se a linguagem por ele utilizada não determinava uma separação de gênero, o mesmo pode ser dito em relação à maneira como organizava as crianças. A partir disso e nessas situações, observamos que as escolhas, relações e práticas construídas pelas crianças não traziam marcas de separação entre meninos e meninas (MARIANO; ALTMANN, 2015, p. 419).

Nessa mesma pesquisa observacional, observou-se como a linguagem utilizada pode gerar dúvida nas meninas a respeito da capacidade delas em alcançar o objetivo da atividade em diferentes momentos e brincadeiras e gerar confiança nos meninos:

Destacamos aqui, uma sequência de falas da professora durante um jogo de queimada, de caráter competitivo, em que foram colocados meninos e meninas em times separados, competindo um contra o outro. Logo no início, várias meninas foram queimadas rapidamente e a professora comentou: "Vocês têm que tentar pegar a bola, vocês estão bobeando e os meninos estão ganhando!". $\mathrm{E}$, em seguida, se dirige aos meninos: "Vamos, vocês estão ganhando!" (MARIANO; ALTMANN, 2015, p. 423).

Em contrapartida, em atividades de grupos mistos, meninos e meninas não foram incentivados de maneira desigual ou as expectativas em torno do resultado de suas ações divergiram e as autoras concluem que "não percebendo diferenças de 
habilidade entre meninas e meninos, o professor não as reforçava. Em outras palavras, não era possível reforçar algo que, na percepção desse professor, não existia" (MARIANO; ALTMANN, 2015, p. 427).

Outros tipos de comunicação, como a comunicação em massa feita pela mídia, são importantes dispositivos propagadores do binarismo, cooperando para a manutenção de uma lógica de dominação-exclusão e silenciando diante das identificações ditas não naturais:

Não é raro observar ações sexistas em programas de humor, em novelas, em artigos de revistas populares brasileiras, seja pelo reforço da ênfase nos papéis sociais - intensificando atitudes, essencialmente masculinas ou femininas -, seja ainda pela rejeição dessas ações - mediante um discurso multicultural que apenas promove o exotismo sem, no entanto, questionar as matrizes sociais, políticas e culturais das diferenças (JESUS, 2014, p. 619).

Sobre brinquedos e o uso da linguagem, a autora deste texto apresenta duas imagens recebidas em aplicativos de mensagens em grupos de mães em que são abordados os brinquedos e a escolha destes com relação ao sexo da criança.

Na Figura 1 propõe-se uma reflexão sobre tipos de brinquedos indicados para meninos e meninas. Se durante a escolha de um brinquedo a resposta para a pergunta "São utilizadas as genitais para brincar com ele?" for "sim", então esse não é um brinquedo para crianças. Em caso de resposta negativa, o brinquedo em questão pode ser utilizado tanto por meninos quanto por meninas. A imagem se mostra como um questionamento tanto à escolha dos brinquedos por sexo quanto à existência de uma dualidade entre crianças. Porém, de certa forma há um resquício de um comportamento já apresentado ao longo deste texto: o adulto apresentado na imagem é uma mulher, que pode deixar subentendido a responsabilidade da mãe na escolha pensada desses brinquedos.

Figura 1- Imagem circulante na internet acerca da escolha de brinquedos para crianças.

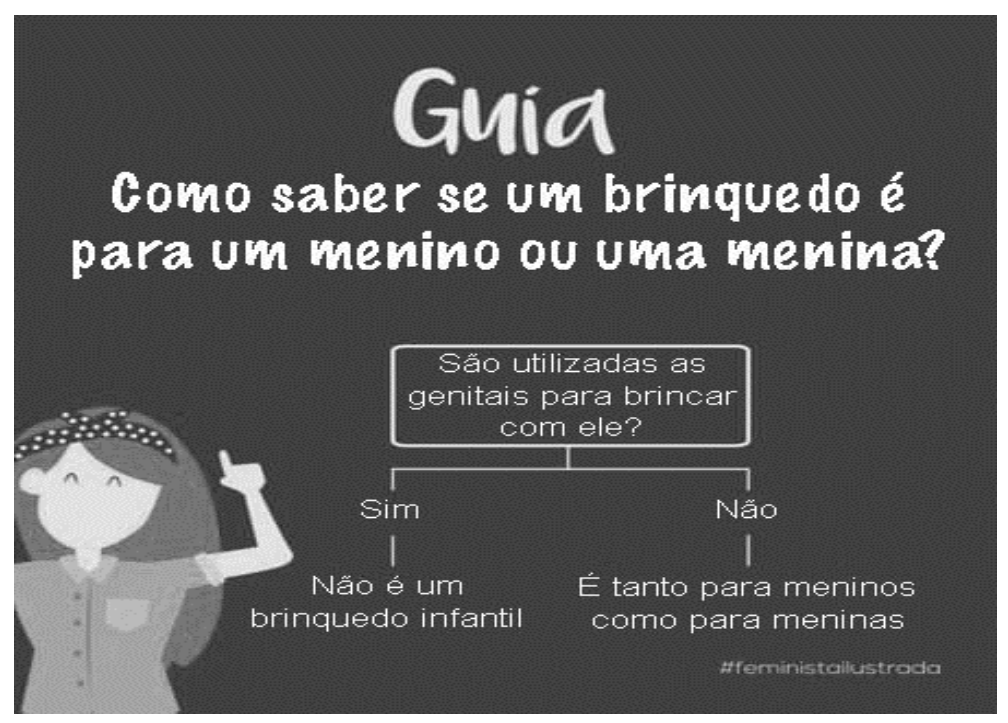

Fonte: https://www.criandocomapego.com/comosaber-se-um-brinquedo-e-para-menina-ou-paramenino/ 
Numa segunda imagem (Figura 2), o questionamento quanto à escolha dos brinquedos é ampliado. Se a reposta para a pergunta "Para brincar precisa usar os órgãos genitais?" for "não", sugere-se que o brinquedo em questão é indicado para todos os gêneros e que assim como o machismo não é bom, o binarismo também não é. A imagem acrescenta o termo "menines" além de meninos e meninas como uma alternativa, além de "meninas" e "meninos". Além disso, não aparecem adultos nem crianças na imagem, não trazendo sugestões de papeis de gênero no cuidado com a escolha dos brinquedos.

\section{Figura 2 - Imagem circulante na internet acerca da escolha de brinquedos para crianças, mas considerando o não binarismo entre meninas e meninos.}

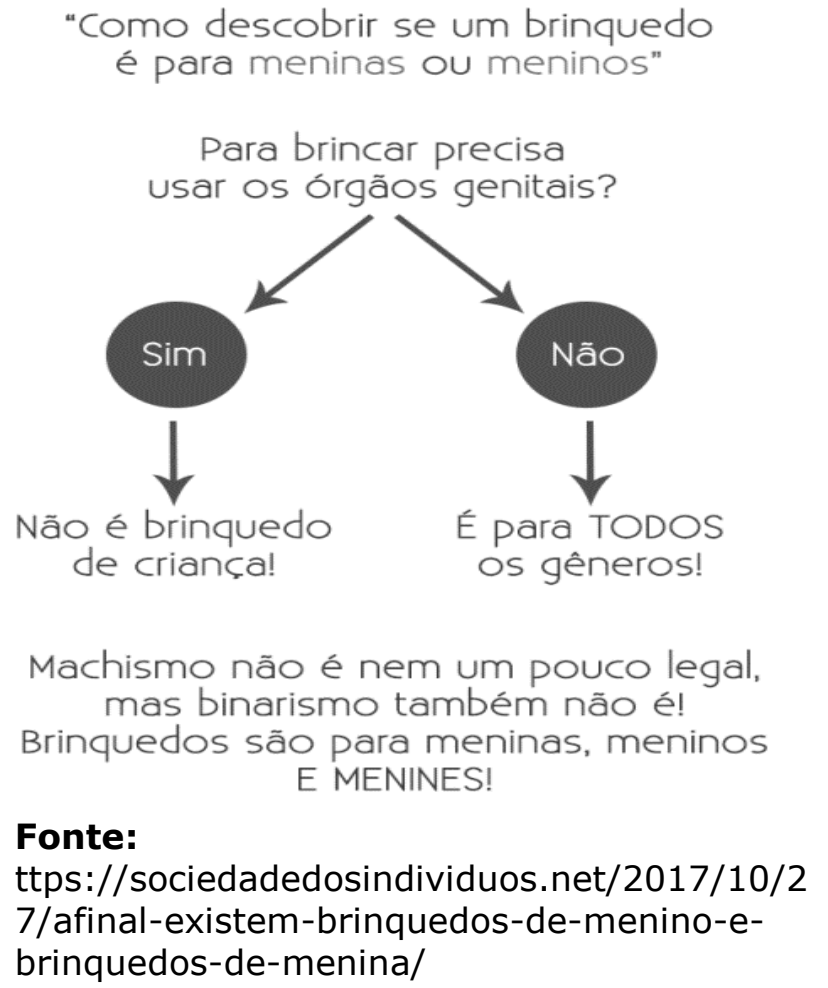

A linguagem tanto pode ser uma forma de reforçar a dualidade entre meninos e meninas e comportamentos esperados de acordo com os papeis de gênero, como pode ser uma ferramenta de acolhimento e estímulo para que as crianças desenvolvam a autonomia e as interações entre os grupos sem criar expectativas ou frustrações acerca do desempenho esperado como consequência do sexo biológico que nasceram.

\section{Considerações finais}

O objetivo deste texto foi trazer reflexões sobre como exercer uma parentalidade ativa para promover a igualdade de gênero entre as crianças, entendendo como a linguagem utilizada e as atividades propostas para grupos de meninos e meninas tem potencial para que desenvolvam habilidades e se relacionem entre si de acordo com suas afinidades. A ideia central do texto foi construída após minhas reflexões enquanto não apenas mãe, mas mãe de menina e que vivencia no dia-a-dia algumas 
situações relacionadas a gênero que trazem questionamento próprio, mas também por parte dela.

Lembro-me de quando fomos confirmar sua matrícula na turma de ballet na escola. Inicialmente, tentei estimulá-la a participar da turma de judô, mas seu desejo foi realmente de ir para o ballet, talvez por influência minha, enquanto bailarina, ou por uma afinidade inerente a ela. Algumas aulas depois, ela me questionou sobre meninos não poderem fazer ballet e poderem praticar apenas o judô. Eu prontamente mostrei vídeos de bailarinos crianças e adultos para que ela soubesse que existiam, apesar de não ser a realidade da escola dela. Ela me respondeu que na escola não tinha roupa de ballet para os meninos, mas que tinha a roupa do judô e isso, para ela, era o que impossibilitava os meninos fazerem ballet mesmo que quisessem.

Esse episódio me levou a pensar no quanto as formas de atribuir papeis de gênero são sutis, mas extremamente eficazes. Mesmo que houvesse um menino com o desejo de fazer parte da turma de ballet e tivesse vencido uma provável rejeição à ideia por parte da família, ele teria que vencer também a barreira da ausência de vestimenta adequada. Acrescento a isso o fato de que, para expressar o desejo de fazer parte da turma, o menino supostamente teria sido apresentado ao ballet, que despertaria sua vontade. Mas, na prática, as turmas são predestinadas às meninas e os meninos direcionados ao judô.

Muito tempo antes disso, ela ainda um bebê, num evento familiar, vesti minha filha com uma peça infantil conhecida popularmente como "body" que havia comprado na "seção masculina" do departamento de roupas para bebês de uma loja, embora a modelagem dessa peça seja a mesma para bebês meninas e meninos, mudando apenas a estampa. Essa peça era predominantemente azul com listras brancas e causou incômodo a alguns familiares por vestir uma menina como se fosse um menino, apenas por conta da cor da peça e da ausência de um outro elemento que trouxesse características femininas.

Relacionar esses acontecimentos, e mais alguns outros não citados aqui por apresentar características similares, com as discussões sobre gênero, identidade de gênero e os papeis socialmente esperados para o sexo biológico me levou a pensar no quanto é importante que essa reflexão comece desde cedo e seja trabalhada tanto nas famílias quanto no contexto escolar. A dualidade entre meninos e meninas imposta pela sociedade pode gerar uma expectativa nas crianças à respeito do que os adultos esperam do comportamento dela, e uma frustração quando essas expectativas não são alcançadas porque a criança não apresenta o desempenho esperado para exercer, no futuro, seu papel de gênero construído pela sociedade e atribuído ao seu sexo biológico.

Permitir que as crianças participem das atividades propostas, sejam atividades de concentração, raciocínio, habilidades domésticas, cuidado com os outros, esportivas e/ou que demandem movimento, desempenho físico e coordenação motora, em grupos mistos pode possibilitar que as crianças entendam que algumas vão ter mais afinidade e melhor desempenho em determinadas atividades e que terão dificuldades em outras e que elas podem ser cooperativas entre si, sem atribuir vantagens ou desvantagens relacionadas ao gênero.

O questionamento da divisão de crianças por grupos, seja quando se é necessário formar equipes ou quando são atribuídas características naturais de cada gênero, recai sobre outros momentos, além de quando se tem várias crianças reunidas. Também pode ser levado para quando adultos que exercem a parentalidade 
ou que convivem com crianças escolhem brinquedos adequados para cada gênero e reforçam a imposição de gênero. Formatos, cores e funções dos brinquedos geralmente vêm com formas de brincar determinadas e um público específico e não possibilitam que as crianças que estão fora daquele público tenham contato com brinquedos diferentes.

Os adultos, cientes do direcionamento dos brinquedos, podem optar por ofertar brinquedos que fujam ao normativo social de gênero. Novamente cito uma situação vivida por mim: minha filha tem muita afinidade por brinquedos de cozinha, mas a grande maioria tem cores atribuídas às meninas, então minha busca foi por esse tipo de brinquedo, mas em cores como vermelho, preto e branco.

O brincar é um momento de desenvolvimento de habilidades e de simulações das atividades dos adultos, então, o contato de crianças com brinquedos que simulem todos os tipos de atividades da rotina da vida adulta pode propiciar que, ao crescerem, sejam mais cooperativos e menos desiguais em termos de gênero seja nas atividades domésticas, na vida social ou nas relações de trabalho.

A sugestão não é que as crianças sejam apresentadas ao oposto do gênero que foi atribuído ao nascimento com a intenção de negá-lo ou que as crianças não tenham seu posicionamento de gênero, mas que seja ofertado o contato com todos os tipos de atividades e brinquedos adequados para a faixa etária.

Neste texto, não foi abordado o tema da sexualidade na infância, mas que é de grande importância inclusive porque, muitas vezes, trabalhar gênero na infância pode ser confundido com sexualização e erotização das crianças, quando a ideia não é trabalhar heterossexualidade ou homossexualidade, mas promover a igualdade de gênero e o respeito às crianças.

Exercer uma parentalidade que não imponha à criança um comportamento que seria o socialmente esperado e permitir que desenvolva sua personalidade e seu posicionamento de gênero com o qual se identifique exige uma desconstrução por parte dos pais ou de quem exerça a parentalidade de uma educação recebida enquanto crianças e uma reconstrução de uma nova forma de educar com base no respeito e no estímulo ao desenvolvimento e aperfeiçoamento de habilidades de acordo com as afinidades da criança na escola e no contexto familiar.

\section{REFERÊNCIAS}

BELOTTI, Elena Gianini. Educar para a submissão. Petrópolis: Vozes, 1975.

BUTTLER, Judith. Gender Trouble: Feminism and the subversion of identity. New York: Routledge; 1990.

CAHILL, Spencer. Language practices and self-definition: the case of gender identity acquisition. The Sociological Quarterly, v. 27, n. 3, p. 295-311, 1986.

CÂMARA NETO, Flávia. O desenvolvimento da sexualidade infantil e a importância da orientação sexual na escola. 2002. 49p. Monografia (Bacharelado em Pedagogia) - Centro de Ciências Humanas, Universidade do Rio de Janeiro, Rio de Janeiro, 2002.

CORDAZZO, Scheila Tatiana Duarte; VIEIRA, Mauro Luís. Caracterização de brincadeiras de crianças em idade escolar. Psicologia: Reflexão e Crítica, v. 21, n. 3, p. 365-373, 2008. Disponível em: https://doi.org/10.1590/S0102-79722008000300004. Acesso em: 18 ago. 2020. 
DIAS, Claudenilson; COELHO, Leonardo. Sexo e gênero [tradução para a língua portuguesa do Capítulo 6, "Sex and Gender", do livro de Ann Oakley, "Sex, Gender and Society" (1972)]. Revista feminismos, v. 4, n. 1, 2016. Disponível em:

https://portalseer.ufba.br/index.php/feminismos/article/viewFile/30206/17837. Acesso em: 18 ago. 2020.

FERREIRA, Maria Manuela M. "- A gente aqui o que gosta mais é de brincar com os outros meninos!": as crianças como atores sociais e a (re)organização social do grupo de pares no cotidiano de um Jardim de Infância. 2002. 646p. Tese (Doutorado em Ciências da Educação). Programa de Pós-graduação em Ciências da Educação, Universidade do Porto, Porto, 2002.

FINCO, Daniela. Educação infantil, gênero e brincadeiras: das naturalidades às transgressões. In: 28a REUNIÃO ANUAL DA ANPED, 2005, Caxambu. Anais... Caxambu, 2005. p. 1-18. Disponível em: https://anped.org.br/biblioteca/item/educacao-infantil-genero-e-brincadeiras-das-naturalidadestransgressoes. Acesso em: 18 ago. 2020.

FINCO, Daniela. Relações de gênero nas brincadeiras de meninos e meninas na Educação Infantil. Pro-Posições, v. 14, n. 42, p. 89-102, 2003. Disponível em:

https://periodicos.sbu.unicamp.br/ojs/index.php/proposic/article/view/8643863. Acesso em 18 ago. 2020.

GREGOVISKI, Vanessa Ruffatto; SILVA, Fernando Lucas Lima; HLAVAC, Lucas André Borges. 'É menino ou menina?' - a construção da identidade de gênero através dos brinquedos. Perspectiva, v. 40, n.152, p. 89-99, 2016. Disponível em:

http://www.uricer.edu.br/site/pdfs/perspectiva/152_597.pdf. Acesso em: 18 ago. 2020.

HIRSCHAUER, Stefan. Dekonstruktion und Rekonstruktion. Plädoyer für die Erforschung dês Bekannten. Feministische Studien, v. 11, n.2, p.55-67, 1993.

JESUS, Dánie Marcelo de. Educados no sexo neutro: a construção discursiva de sexualidade e de gênero em um texto da revista Veja. Revista Brasileira de Linguística Aplicada, v. 14, n. 3, p. 613-634, 2014. Disponível em: https://doi.org/10.1590/S1984-63982014005000018. Acesso em: 18 ago. 2020.

JESUS, Jaqueline Gomes de. Orientações sobre identidade de gênero: conceitos e termos. 2 . ed. Brasília: Fundação Biblioteca Nacional, 2012.

LOURO, Guacira Lopes. Currículo, gênero e sexualidade. Porto: Porto Editora, 2000.

MARIANO, Marina; ALTMANN, Helena Educação Física na Educação Infantil: educando crianças ou meninos e meninas? Cadernos Pagu, v.46, p. 411-438, 2016. Disponível em:

https://doi.org/10.1590/18094449201600460411. Acesso em: 18 ago. 2020.

ORGANIZAÇÃO MUNDIAL DA SAÚDE. Defining sexual health: report of technical consultation on sexual health. Geneva; 2006. 35p.

PEDRO, Joana Maria. Traduzindo o debate: o uso da categoria gênero na pesquisa histórica História, v. 24, n. 1, p.77-98, 2005. Disponível em: https://doi.org/10.1590/S010190742005000100004. Acesso em: 18 ago. 2020.

RIBEIRO, Moneda Oliveira; DIAS, Aretuzza de Fátima. Child-juvenile prostitution: a systematic literature review. Revista da Escola de Enfermagem da USP, v. 43, n. 2, p. 465-71, 2009. Disponível em: https://doi.org/10.1590/S0080-62342009000200029. Acesso em 18 ago. 2020.

SCOTT, Joan Scott. Gender and the politics of history. New York: Columbia University Press; 1999. 
SILVA, Ariana Kelly Leandra Silva da. Diversidade sexual e de gênero: a construção do sujeito social. Revista do NUFEN, v. 5, n. 1, p. 12-25. 2013. Disponível em:

http://pepsic.bvsalud.org/pdf/rnufen/v5n1/a03.pdf. Acesso em: 18 ago. 2020.

STOLLER, Robert Stoller. Sex and gender: the development of masculinity and femininity. New York: Science House; 1968.

THORNE, Barrie. Gender Play: girls and boys in school. Buckingham: Open University, 1993.

VIANNA, Cláudia; FINCO, Daniela. Meninas e meninos na Educação Infantil: uma questão de gênero e poder. Cadernos Pagu, v. 33, p. 265-284, 2009. Disponível em:

http://dx.doi.org/10.1590/S0104-83332009000200010. Acesso em: 18 ago. 2020.

Recebido em: 20 de agosto de 2020.

Aceito em: 10 de outubro de 2020.

Publicado em: 05 de janeiro de 2021. 